SOCIO-PSYCHOLOGICAL ANALYSIS OF GREEN CONSUMER BEHAVIOUR: WITH SPECIAL REFERENCE TO MARKETING INFORMATION ON ATTITUDINAL BEHAVIOUR

\author{
BY \\ D. S. Rohini Samarasinghe
}

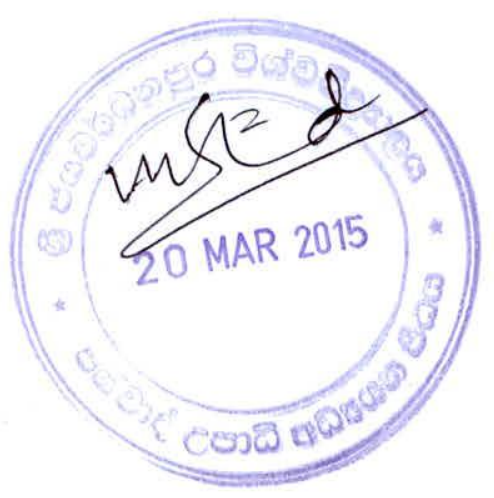

Thesis submitted to the University of Sri Jayewardenepura for the award of the Degree of Doctor of Philosophy in Sociology on $28^{\text {th }}$ February 2014 


\section{DECLARATION OF THE CANDIDATE}

The work described in this $\mathrm{PhD}$ thesis was carried out by me under the supervision of Professor Swarnalatha Perera and Professor Tenyson Perea, of the Department of Sociology and Anthropology of the University of Sri Jayewardenepura. I certified that this thesis has not been submitted in whole or in part to any University or any other institution or any other Degree or Diploma. Also, I declare that all the corrections, amendments, and additions recommended by the examiners have been incorporated.

Signed by,

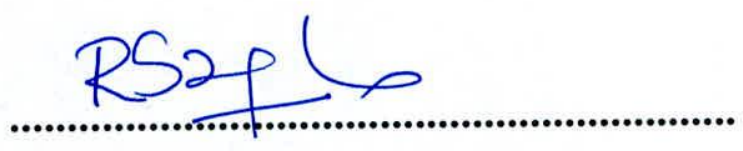

\section{$18 \cdot 03 \cdot 2015$}

D. S. Rohini Samarasinghe

Date

PhD Candidate 


\section{DECLARATION OF THE SUPERVISORS}

I certify that the candidate has incorporated all corrections, amendments, and additions recommended by the examiners.

Signed by,

\section{WPerena.}

Professor Swarnalatha Perera

Supervisor

University of Sri Jayewardenepura

Gangodawilla

Nugegoda

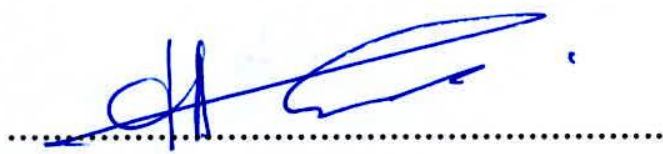

Professor Tenyson Perera

Supervisor

Department of Sociology \& Anthropology

University of Sri Jayewardenepura

Gangodawilla

Nugegoda

\section{$18 \cdot 03 \cdot 2015$}

Date

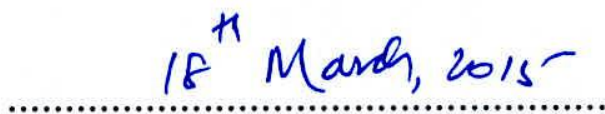

Date 


\section{Acknowledgement}

I would like to express my sincere gratitude to all those who gave me the possibility and encouragement to complete this thesis. I am grateful to the University of Sri Jayewardenapura, Sri Lanka, my employer and the Department of Sociology and Anthropology for facilitating me to pursue my doctoral studies.

Foremost, I would like to express my sincere gratitude to my research supervisor Professor Dr. Swarnalatha Perera for the continuous support, patience, motivation, enthusiasm, and immense knowledge provided. Her guidance helped me in all the time of research and writing of this thesis. I would also like to express my unending gratitude to Professor Tenyson Perera who ended up being a mentor through this process. His guidance helped me throughout my study and writing of this thesis. His dedication, understanding and the experience I will never forget.

Further, I would like to thank Dr. Siti Hussna Chairperson of the Marketing Management Department at University Sains Malaysia provided an extended support me to do literature in green marketing and guidance on Structural Equation Modeling data analysis for facilitating me to work as a visiting PhD student. I would also like to thank Dr. Nilakshi Galahitiya, senior lecturer at University of Sri Jayewardenepura for helping me to carry out an extensive statistical data analysis for this thesis. I like to thanks my staff and colleagues for their moral support especially who provided a generous assistance for data collection.

The completion of this work would not have been possible without the love, support, and sacrifices of my husband Wijaya, and my two children Sachintha and Thathsarani. Their sacrifices enabled me to live my dream of becoming a PhD holder. Ultimately, I am indebted to my parents for instilling in me the values of hard work and dedication to accomplishing this goals, I could pay gratitude for my parents who devoted whole life on behalf of children's well being. 


\section{Table of Contents}

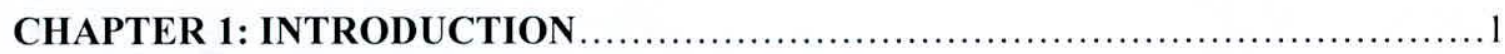

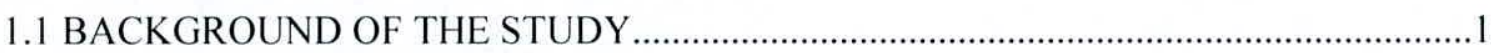

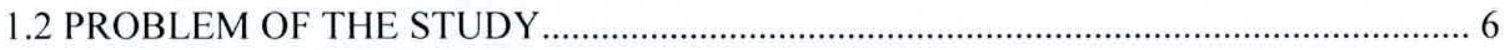

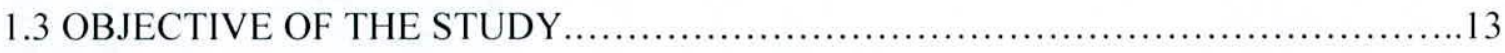

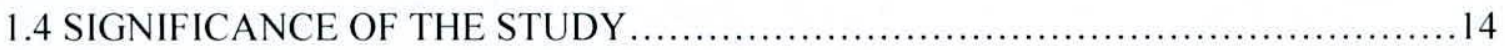

1.4.1 Theoretical Significance \& Contribution ......................................................................15

1.4.2 Social Significance \& Managerial Contribution ....................................................... 16

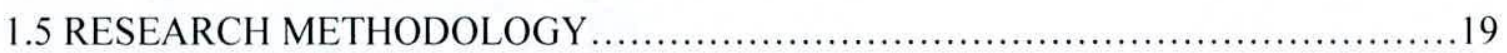

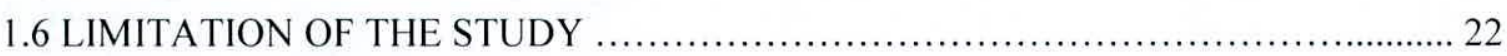

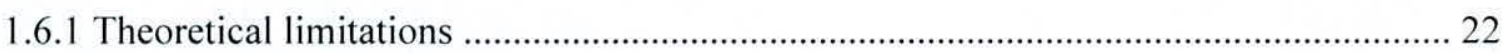

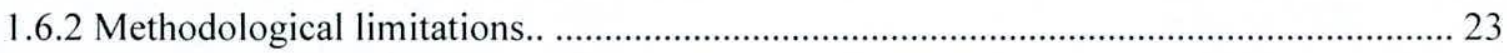

1.7 STRUCTURE OF THE THESIS..................................................................................... 24

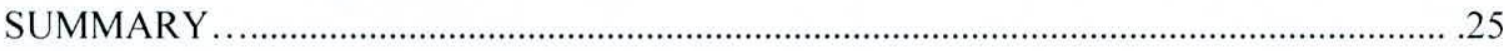

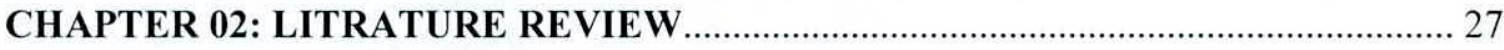

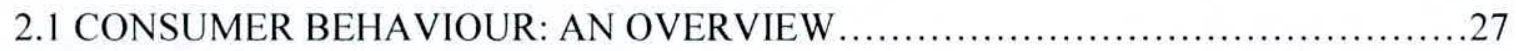

2.2 THEORETICAL LITERATURE OF ATTITUDE \& BEHAVIOUR................................. 31

2.2.1 Attitude - Behaviour in Social Psychological Perspective ………………………….....32

2.2.2 Nature and Components of Attitude to Approach the Study ........................................... 34

2.2.3 Values in Environmental Social- Psychology ………….............................................36

2.2.4 Beliefs in Environmental Social- Psychology ………………………………………......38

2.2.5 Norms in Environmental Social- Psychology …………………………………….....40

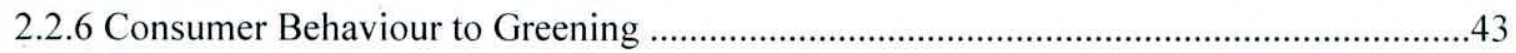


2.2.8 Relationship of Green Consumers and their Attitudinal Behaviour .... 48

2.2.9 General Theories to Green Consumer Attitudinal Behaviour 49

2.2.10 Altruism \& Pro-Social Behaviour Theories to Green Consumer Attitudinal Behaviour56

2.2.11 Theories Applied in the Present Research Domain 62

2.3 EMPIRICAL LITERATURE 65

2.3.1 Empirical Research Gaps in Literature 65

2.4 DEVELOPMENT OF RESEARCH MODEL AND HYPOTHSES. 71

2.4.1 Conceptual Research Model .71

2.4.2 Hypotheses Development .73

2.4.2.1 Causal Relationship to Green Attitudinal Behaviour. 73

2.4.2.2 Direct Effect of Green Marketing Information to Attitudinal Factors .81

2.4.2.3 Moderating Effect of Green Marketing Information to Attitudinal Factors...... 85

2.4.2.4 Relationship between Green Behaviour Intention and Actual Behaviour. 87

SUMMARY .89

CHAPTER 03: METHODOLOGY 90

3.1. RESEARCH DESIGN 90

3.1.1. Research Method: Survey Strategy .94

3.1.2. Population of the Study 94

3.1.3. Sampling Framework .95

3.1.4. Unit of Analysis 97

3.2. SAMPLING

3.2.1. Sampling Method .97

3.2.2. Sample Size .99 
3.3.1 Dependent (Criterion) Variable 1: Actual Green Behaviour .......................................101

3.3.2 Mediating Variable: Green Behaviour Intention ........................................................ 103

3.3.3 Independent (Predictor) Variable: Components of Green Attitudes ............................105

3.3.4. Moderating Variable: Green Marketing Information (GIO) ......................................112

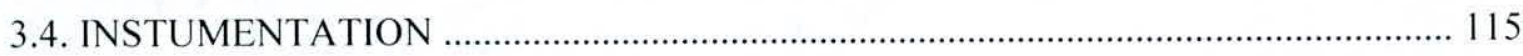

3.4.1 Questionnaire: Section A- Chain/Components of Attitude ...................................... 116

3.4.2 Questionnaire: Section B - Green Marketing Information (GIO) ................................ 120

3.4.3 Questionnaire: Section C - Green Behaviour Intention (GBI) …............................ 121

3.4.4 Questionnaire: Section D- Actual Green Behaviour (AGB) …....................................123

3.4.5 Questionnaire: Section E- Consumer Demographics ................................................ 125

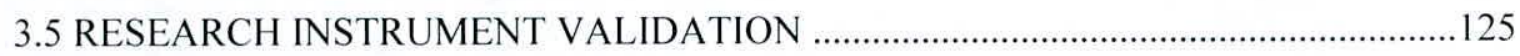

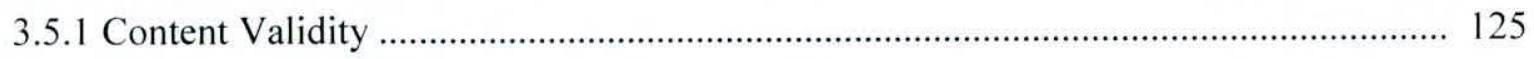

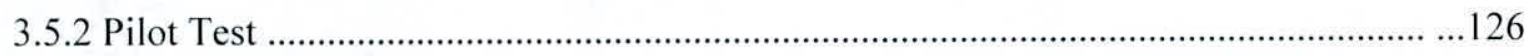

3.6 DATA COLLECTION PROCESS....................................................................... 135

3.6.1 Quantitative Data Collection: Consumer Survey ….................................................135

3.6.2 Qualitative Data Collection: In-Depth Interviews \& Observations .............................137

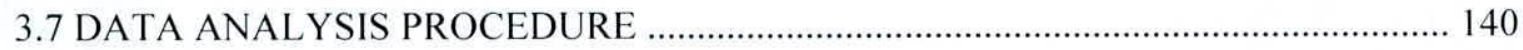

3.7.1 Quantitative Data Analysis: Consumer Survey ................................................. . 140

3.7.2 Qualitative Data Analysis: In-Depth Interviews \& Observation ............................... 144

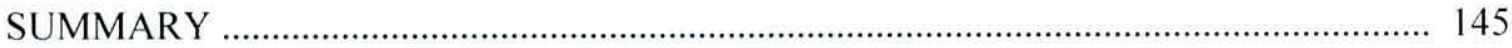

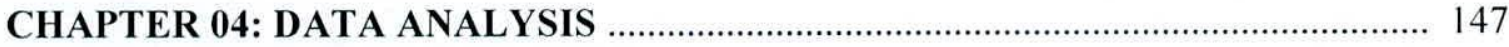

4.1 DATA PRESENTATION FOR ANALYSIS ............................................................. 147

viii 
4.1.1 Demographic Profile 148

4.2 DISCRIPTIVE STATISTICS. 150

4.2.1 Components of Green Attitude -1: Green Value Orientations 150

4.2.2 Components of Green Attitude -2: Green Beliefs (GB)

4.2.3 Components of Green Attitude -3: Green Norms (GN) 152

4.2.4 Green Information Orientation

4.2.5 Green Behaviour Intention (GBI)...

4.2.6 Actual Green Behaviour (AGB)..

4.3.1 Normality

4.3.2 Linearity 157

4.3.3 Multicollinearity 160

4.4 MEASURE REFINMENT AND VALIDATION 163

4.4.1 Unidimensionality 163

4.4.2 Reliability 176

4.4.3 Validity 182

4.4.4 Confirmatory Factor Analysis in Structural Equation Modeling (SEM). 184

4.5 MEASUREMENT OF CONCEPTUAL STUDY MODEL 185

4.5.1 PLS Analysis Results of Measurement Model (MM) 188

4.5.2 PLS Analysis Results of Structural Model (SM) 205

4.6 HYPOTHESES TESTING. 212

4.6.1 Structural Model for Direct Effect between Components of Green Attitude. .213

4.6.1.1 Hypotheses Testing Results: Hypothesis One 
4.6.2 Structural Model for Direct Effect of Components of Attitude to Green Behaviour... 216

4.6.2.1 Hypotheses Testing Results: Hypothesis Four

4.6.2.2 Hypotheses Testing Results: Hypothesis Six

4.6.2.3 Hypotheses Testing Results: Hypothesis Eight.

4.6.3 Structural Model for Direct Effect of Green Information on Attitude and Behaviour....220

4.6.3.1 Hypotheses Testing Results: Hypothesis Nine 221

4.6.3.2 Hypotheses Testing Results: Hypothesis Ten 222

4.6.3.3 Hypotheses Testing Results: Hypothesis Eleven 223

4.6.3.4 Hypotheses Testing Results: Hypothesis Thirteen .225

4.6.4 Hypotheses testing Results of Moderating Effect of Green Information (GIO) on to the Relationship between Components of Attitude and Behaviour

4.6.4.1 Hypotheses Testing Results: Hypothesis Fourteen 229

4.6.4.2 Hypotheses Testing Results: Hypothesis Sixteen 231

4.6.4.3 Hypotheses Testing Results: Hypothesis Seventeen 232

4.6.4.4 Hypotheses Testing Results: Hypothesis Nineteen 234

4.6.4.5 Hypotheses Testing Results: Hypothesis Twenty One 235

4.7 ANALYZING QUALITATIVE DATA 238

4.7.1 Emerging Realities from Qualitative Data.. 239

4.7.1.1 Qualitative Insights of Consumers' Attitudes about 'Green Concept' 239

4.7.1.2 Qualitative Insights of Consumers' Attitudes towards Actual Green Behaviour. .243

4.7.1.3 Qualitative Insights of Consumers' Attitudes towards Green Information .247 SUMMARY 251 
5.1.1 Findings of Objective One: .253

5.1.2 Finding of Objective Two: .258

5.1.3 Findings of Objective Three: .260

5.1.4 Findings of Objective Four: .267

5.1.5 Findings of Objective Five: 273

5.2 IMPLICATIONS OF THE STUDY 279

5.2.1 Implications for Green Attitudinal Behaviour .279

5.2.2 Implications for Green Marketing Information on Green Attitudinal Behaviour .282

5.3 CONTRIBUTIONS OF THE STUDY 286

5.3.1 Contribution to Theory. .286

5.3.2 Contribution to Methodology 288

5.3.3 Contribution to Social \& Managerial Practices. .289

5.4 LIMITATIONS AND DIRECTION FOR FUTURE RESEARCH 290

5.5 CONCLUSION 292

REFERENCES .294

APPENDIES 310 


\section{List of Figures}

Figure 2.1: Consumer Behaviour as the Study of Consumer 28

Figure 2.2: A Model of Consumer Behaviour as a Multidisciplinary Field 29

$\begin{array}{ll}\text { Figure 2.3: Literature Path Diagram } & 30\end{array}$

Figure 2.4: Early US Linear Models of pro-environmental Behaviour $\quad 50$

Figure 2.5: The theory of Reasoned Action $\quad 52$

Figure 2.6: The Theory of Planned Behaviour (TPB) 53

Figure 2.7: The Model of Responsible Environmental Behaviour $\quad 55$

Figure 2.8: A Systematic Presentation of Variables in VBN Theory 58

Figure 2.9: The Conceptual Study Model $\quad 72$

Figure 3.1: Mixed Method Research Designs 91

Figure 3.2 The Mixed Methodology Cycle Summarising the Research Process for $\quad 93$ this Study

Figure 4.1: Scatter plot and Linearity in the Relationship between Green Value

Orientations and Green Beliefs

Figure 4.2: Scatterplot and the in the Linearity Relationship between Green Beliefs and Green Norms

Figure 4.3: Scatterplot and the in the Linearity Relationship between Green Norms and Green Intention

Figure 4.4: Scatterplot and the Linearity in the Relationship between Green Intention and Actual Green Behaviour

Figure 4.5: Inner Model and Outer Model in PLS Path Model

Figure 4.6:The Basic Structural Model (SM) of the PLS Path Graph 207

Figure 4.7: The Final Structural Model (SM) of the PLS Path Graph 210

Figure 4.8: Structural Path Model for Association between GVO and GB 214

Figure 4.9: Structural Path Model for Association between GB and GN 215

Figure 4.10: Structural Path Model for Association between GVO and AGB 217

Figure 4.11: Structural Path Model for Association between GB and AGB 218

Figure 4.12: Structural Path Model for Association between GN and AGB 219 
Figure 4.13: Structural Path Model for Direct effect of GIO on GVO

Figure 4.14: Structural Path Model for Direct effect of GIO on GB

Figure 4.15: Structural Path Model for Direct effect of GIO on GN

Figure 4.16: Structural Path Model for Direct effect of GIO on AGB

Figure 4.17: Structural Path Model for the Moderating Effect of GVO and GB on to the Relationship of GIO

Figure 4.18: Structural Path Model for the Moderating Effect of GVO and AGB on to the Relationship of GIO

Figure 4.19: Structural Path Model for the Interaction Effect of GB and GN on to the Relationship of GIO

Figure 4.20: Structural Path Model for the Interaction Effect of GB and AGB on to the Relationship of GIO

Figure 4.21: Structural Path Model for the Interaction Effect of GN and AGB on to the Relationship of GIO

Figure 5.1: Findings Summary of Path Graph for the Interaction Effect of Chain of Attitude

Figure 5.2: Findings Summary of Path Graph for the Direct Effect of Chain of

Attitude on Actual Green Behaviour (Without Green Information Effect)

Figure 5.3: Finding Summary of Path Graph for the Direct Effect of Chain of

Attitude on Actual Green Behaviour (With Direct Effect of Green Information)

Figure 5.4: Finding Summary of Path Graph for the Effect of Chain of Attitude on Actual Green Behaviour (With Moderating Effect of Green Information) 


\section{List of Tables}

Table 1.1:Summary of Methodology 21

Table 2.1: Attitude-Behaviour Theories for Study of Green Consumer Behaviour $\quad 59$

Table 3. 1 Sample selection $\quad 98$

Table 3.2: Summary of Sample Selection $\quad 100$

Table 3.3: Operationalization of Actual Green Behaviour 103

Table 3.4: Operationalization of Green Behaviour Intention 104

Table 3.5: Operationalization of Green Value Orientation 107

$\begin{array}{ll}\text { Table 3.6: Operationalization of Green Beliefs } & 109\end{array}$

$\begin{array}{ll}\text { Table 3.7: Operationalization of Green Norms } & 110\end{array}$

$\begin{array}{ll}\text { Table 3.8: Different Views of Green Marketing Information } & 113\end{array}$

Table 3.9: Operationalization of Green Marketing Information $\quad 114$

Table 3.10: Questions: Green Value Orientations (GVO) 117

Table 3.11: Questions: Green Beliefs (GB) 118

Table 3.12 :Questions: Green Norms (GN) 119

Table 3.13 :Questions: Green Marketing Information (Orientation) (GIO) 120

Table 3. 14 :Questions: Green Behaviour Intention (GBI) 122

Table 3. 15: Questions: Actual Green Purchasing Behaviour (AGB) 124

Table: 3.16 :Results of Pilot Study: Reliability Statistics $(\mathrm{n}=50)$

Table 3.17: Results of Pilot Study: Green Value Orientations $(n=50) \quad 129$

Table 3.18: Results of Pilot Study: Green Beliefs $(n=50) \quad 130$

Table 3.19: Results of Pilot Study: Green Norms ( $\mathrm{n}=50)$

Table 3.20: Results of Pilot Study: Green Information Orientations $(n=50)$

Table 3.21: Results of Pilot Study: Green Behaviour Intention $(n=50) \quad 133$

Table 3.22: Results of Pilot Study: Actual Green Behaviour $(n=50) \quad 134$

Table 3.23: Checklist (Open-Ended Questionnaire) for In-Depth Interviews 138

Table 4.1: Demographic Profile of Survey Respondents 149

Table 4.2: Descriptive Statistics for the Green Value Orientations (GVO) 151

Table 4.3: Descriptive Statistics for Green Beliefs (GB) 152

Table 4.4:Descriptive Statistics for Green Norms (GN) 152 
Table 4.5:Descriptive Statistics for Green Information Orientation (GIO)

Table 4.6:Descriptive Statistics for Green Behaviour Intention (GBI)

Table 4.7:Descriptive Statistics for Actual Green Behaviour (AGB)

Table 4.8:Skewness and Kurtosis Statistics

Table 4.9:Collinearity Statistics for Constructs

Table 4.10:Pearson Correlation Coefficients

Table 4.11:KMO and Bartlett's Test for the Construct

Table 4.12:The EFA Results of Green Value orientation (GVO)

Table 4.13:The EFA Results of Green Beliefs (GB)

Table 4.14:The EFA Results of Green Norms (GN)

Table 4.15:The EFA Results of Green Information Orientation (GIO)

Table 4.16:The EFA Results of Green Behaviour Intention (GBI)

Table 4.17:The EFA Results of Actual Green Behaviour (AGB)

Table 4.18:Cronbach's Alpha Reliability

Table 4.19:PLS results for Consumers' Green Value Orientation

Table 4.20:PLS Final results for Consumers' Green Value Orientation

Table 4.21:PLS Results for Consumers' Green Beliefs

Table 4.22:Final PLS results for Consumers' Green Beliefs

Table 4.23: PLS results for Consumers' Green Norms

Table 4.24: PLS Final results for Consumers' Green Norms

Table 4.25: PLS results for Consumers' Green Information Orientation

Table 4.26: Final PLS results for Consumers' Green Information Orientation

Table 4.27: PLS results for Consumers' Green Behaviour Intention

Table 4.28: Final PLS results for Consumers' Green Behaviour Intention

Table 4.29: PLS Results for Consumers' Actual Green Behaviour

Table 4.30: Final PLS Results for Consumers' Actual Green Behaviour

Table 4.31: Results of Reliability \& Validity Measures

Table 4.32: Squared Inter-construct Correlations and AVE Matrix for Discriminant

Validity

Table 4.33: Results of Reliability \& Validity Measures for Final Model 
Validity for Final Model

Table 4.35: Summary of PLS Results with All Variables

Table 4.36: Summary of PLS Results for Final Path Model

Table 4.37: Summary of Hypotheses Testing Results on Direct paths to Components

of Attitude

Table 4.38: Summary of Hypotheses Testing Results on Direct paths to Components of Attitude to Behaviour

Table 4.39: Summary of Hypotheses Testing Results on Direct Effect of Green

Information on Components of Attitude to Behaviour

Table 4.40: Summary of Hypotheses testing Results of Moderating Effect of Green

Information on to the Relationship of Components of Attitude and Behaviour

Table 5.1: Summary of Descriptive Data Analysis

\section{List of Appendices}

Appendix 1: Questionnaire for the Pilot Survey 310

Appendix 2: Questionnaire for Final Data Collection 322

Appendix 3: Boxplot 333

Appendix 4: Results Of Exploratory Factor Analysis 334

Appendix 5: $\quad$ Results Of Outer Loading In Measurement Model 343

Appendix 6: Results Of Cross Loading In Measurement Model 345

Appendix 7: $\quad$ Measuring The Total Effect Of Green Information On Chain Of Green 346 Attitude And Behaviour

Appendix 7-a: Basic Structural Model For Effect Of Green Information On Chain Of 349 Green Attitude And Behaviour

Appendix 7-b: Basic Structural Model For Effect Of Green Information On Chain Of 350 Green Attitude And Behavior - T Values

Appendix 8: $\quad$ Measuring The Total Effect Of Green Information On Chain Of Green Attitude And Behaviour (Dropping Green Behaviour Intention) 
Appendix 8-a: Basic Structural Model For Effect Of Green Information On Chain Of

Green Attitude And Behavior- Path Coefficents \& R2 Values

Appendix 8-b : Basic Structural Model For Effect Of Green Information On Chain Of Green Attitude And Behavior - T Values

Appendix 9: Measuring The Total Effect Of Green Information On Chain Of Green

Attitude And Behaviour (Direct Effect Of Green Marketing

Information)

Appendix 9-a: Basic Structural Model For Effect Of Green Information On Chain Of Green Attitude And Behavior- Path Coefficents \& R2 Values

Appendix 9-b: Basic Structural Model For Effect Of Green Information On Chain Of Green Attitude And Behavior - T Values

Appendix 10: $\quad$ Measuring The Total Effect Of Value, Belief, And Norm To Green Attitude And Behavior

Appendix 10-a: Measuring The Total Effect Of Value, Belief, And Norm To Green Attitude And Behavior - Path Coefficents \& R2 Values

Appendix 10-b: Appendix 10 B: Measuring The Total Effect Of Value, Belief, And 359 Norm To Green Attitude And Behavior - T- Values 


\begin{abstract}
Green consumer behaviour is gaining increasing importance as propensity to take actions with pro-environmental intent. People's attitudes regarding green values, beliefs and norms of different aspects of the full cycle of environmentally friendly purchasing, using and disposing behaviour have become an important consideration in human decision making. Green marketing information has become the key messenger for consumers to a make choice of green consumption related decisions. It is widely cited in social psychological research, the existence of attitude-behaviour gap in behavioural choices, but it is not yet empirically investigated how green information can be used to overcome this gap. Therefore, the objective of this study is to elucidate the impact of green information on the antecedents of green attitudes (Values-BeliefsNorms) towards actual green consumer behaviour. The research initially undertakes a comprehensive literature review on socio-psychological theoretical models of green consumer attitudinal behaviour to develop the necessary theoretical study model of identifying the role of green marketing information as the empirical research gap. The theory of Value-Belief-Norm (VBN Theory) served as the theoretical framework for this study.
\end{abstract}

Research Philosophy of the study is based on neo-positivistic research tradition which facilitated the research task to acquire and gain knowledge for understanding the emergence of green consumer behaviour in the Sri Lankan context. Therefore, the present study used explanatory mixed-method' research process in order to strategically achieve the broader research objective. The descriptive findings of this research demonstrate that Sri Lankan consumers have moderate level of green values, beliefs and norms, but the moral obligation towards actual green behaviour 
is rather low. This explains that green attitude-behavior gap is common to the Sri Lankan context as in the other developed world.

Green information seems to be more complicated aspect that needs to be properly managed in green consumption attitude formation and changing process as better predictor to minimize the gap between attitude-behaviour. Especially, Sri Lankan consumers do not have much trust in available green information. This seems to lead 'green washing'. Therefore marketers and policy makers need to provide accurate, clear, meaningful and understandable green information to consumers as it is a powerful strategy for activating and changing green attitudes to green consumption behaviour to achieve sustainable competitive advantage. Consequently, truthful green information can offer ample opportunities for activating green values, beliefs and norms for application in green behavioural change in Sri Lanka. Meanwhile, the consumer should consider available information about the green products while referring to information at the point of purchase and other available green promotional activities to become more environmentally friendly consumers.

Multivariate statistical analysis in Structural Equation Method shows that green beliefs seem to be a more powerful predictor for green behaviour in Sri Lanka. Green beliefs play a dual role between green norms and green behaviour, i.e. Sri Lankans' green beliefs are mediated between green values and green norms confirming the antecedents of value, belief and norm in VBN theory while consumers' green beliefs directly and positively impact on green behaviour somewhat deviating from the theoretical argument. Qualitative analysis supported that attachment of the Sri Lankans with their religious (i.e. KARMA) and cultural beliefs are higher 
than the moral responsibility towards green behaviour. This finding is a novelty in Sri Lankan context.

In addition, the empirical verification of the moderating role of green marketing information between green attitude and behaviour relationships are some of the main contributions to the theory. The influence of moderating role of green information in Sri Lankan context seems to be more controversial and questionable. Therefore, proposed integration of social psychological theory in green consumer behaviour model leads to interesting social and managerial implications for policy makers, researchers, marketers and information providers involved in green production and the marketing process.

This research has contributed to the area of green consumption behaviour. To the author's knowledge, this is the first research providing a comprehensive overview and linking the social psychological literature on green consumer behaviour to the VBN Theory, including the green marketing information. The study contributes to the body of knowledge and it provides validated measurement constructs for green behaviour in the Sri Lankan context. 